\title{
AUTONOMIA E DESENVOLVIMENTO COMO IDEIAS CONSTITUTIVAS NA COOPERAÇÃO ENTRE ARGENTINA E BRASIL NA ÁREA NUCLEAR
}

\section{Autonomy and development as constitutive ideas in the nuclear cooperation between Argentina and Brazil}

\section{Introdução}

O incremento de iniciativas e programas na área nuclear constituiu-se como um aspecto relevante, tanto no plano interno, quanto no tocante ao relacionamento e à percepção do contexto internacional para Argentina e Brasil. O percurso das atividades nucleares nos dois países está ligado a uma concepção que vai além da vinculação entre a energia nuclear e uma forma de suprir necessidades energéticas. A jornada pelo domínio da tecnologia nuclear é perpassada pela sua associação com questões mais amplas, como desafios ao desenvolvimento tecnológico de ponta, as relações com as potências e a melhoria de condições econômicas internas, ou seja, com questões que se referem à autonomia e ao desenvolvimento.

O relacionamento entre Argentina e Brasil é historicamente marcado por oscilações entre tônicas de rivalidade e cooperação. A primeira predominou desde a criação dos dois Estados, até a década de 1980. Mello (1996) caracteriza como pendular o movimento entre essas lógicas. A rivalidade era marcada por suspeitas, desconfianças e concorrência por influência e superioridade regional. Soares e Lima (2013) destacam que as relações bilaterais são mais bem entendidas como marcadas pela concorrência do que uma afrontosa rivalidade, uma vez que foram constantemente evitados altos níveis de confronto. Como Redick (1981, p. 130) afirmaria sobre a rivalidade entre Argentina e Brasil na área nuclear, sua natureza é quase 'cavalheiresca'.

\footnotetext{
${ }^{1}$ Mestra e Doutoranda em Relações Internacionais pelo Programa de Pós-Graduação em Relações Internacionais San Tiago Dantas (UNESP -UNICAMP - PUC-SP). Membro do Grupo de Estudos de Defesa e Segurança Internacional (GEDES). Professora do curso de graduação em Relações Internacionais da Universidade Paulista (UNIP). Email: luiza.januario@unesp.br

${ }^{2}$ Professor associado da Universidade Estadual Paulista (UNESP) e do Programa de Pós-Graduação em Relações Internacionais San Tiago Dantas (UNESP, UNICAMP, PUC-SP). Pós-doutor em Relações Internacionais pela Georgetown University, pelo Instituto Gutierrez Mellado. Doutor e mestre em Ciência Política pela Universidade de São Paulo (USP) e bacharel em Ciências Sociais pela mesma universidade. Membro do Grupo de Estudos de Defesa e Segurança Internacional (GEDES). Email: samuel.soares@unesp.br
} 
De qualquer forma, uma lógica mais cooperativa começou a ganhar destaque em meados da década de 1980. Um antecedente importante para essa dinâmica foi o Acordo de Itaipu e Corpus de 1979 (MATHIAS; GUZZI; GIANNINI, 2008), uma vez que colocou fim a uma disputa pela utilização do rio Paraná que travava o diálogo. Pode-se apontar também que a crise do canal de Beagle levou à percepção de que era necessária uma postura mais moderada no Prata, permitindo a realização do acordo citado. Camargo (1985, p. 63) ressalta que no final dos anos 1970 houve espaço para a identificação de convergências entre os dois países ao afirmar que ocorreu um "avanço na percepção da existência de identidades reais e complementaridades potenciais que poderiam permitir entendimentos efetivos”. Esforços passaram então a ser promovidos no sentido de uma maior aproximação e levam ao que Marinho (2017) caracteriza como fraternidade oficial. Contudo, esses intentos não significaram a existência de convergências totais e imutáveis, nem que a desconfiança tenha desaparecido totalmente.

Tais iniciativas coligam-se às ideias de autonomia e desenvolvimento, orientadoras dos debates e de parte das ações referentes às atividades e aos programas nucleares de Argentina e Brasil e na aproximação bilateral nesta área. No início dos esforços nesse campo, havia uma lógica de competição e desconfiança, podendo a rivalidade nuclear ser considerada uma manifestação tecnológica moderna de um longo processo de competição e emulação (CARASALES, 1995). Oelsner (2005) identifica as razões que fundamentam a rivalidade na busca por poder, prestígio, desenvolvimento, superioridade tecnológica e científica em relação à América Latina e aspiração à liderança regional. Por sua vez, Oliveira (1996) considera que o desenvolvimento dos setores nucleares foi um tema sensível, porque a concorrência apresentava contornos mais complexos com a possibilidade de uma competição pautada por uma corrida armamentista nuclear. Vargas (1997) apresenta a questão em termos mais centrais, do ponto de vista da segurança estatal, defendendo que a rivalidade era baseada em uma suposta ameaça recíproca à integridade e às soberanias nacionais. Já Mallea e Spektor (2015) avaliam que a rivalidade nuclear se deu em um contexto de suspeitas externas sobre os interesses por trás dos programas dos dois países, sendo que a busca de cada um deles por dominar os aspectos mais sensíveis do ciclo do combustível gerou desconfianças, agravadas pelo sigilo das atividades e por um baixo grau de contato diplomático de alto nível.

Esse quadro foi alterado ao longo dos anos. Em 1980 foi dado um primeiro passo para a aproximação de Argentina e Brasil na temática, com a divulgação de uma declaração conjunta e iniciativas de cooperação ganharam impulso especialmente a partir de 1985. Em 1968-70, 1970-72, 1974 e 1979 ocorreram embriões de tentativas de cooperação entre os dois países que, apesar de não terem sido conclusivas, evidenciaram a existência da perspectiva de que uma aproximação poderia ser proveitosa (MALLEA, 2012). Em 1991, foi criada a Agência Brasileiro-Argentina de Contabilidade e Controle de Materiais Nucleares (ABACC), um arranjo sui generis no âmbito das salvaguardas nucleares (OLIVEIRA; CANTO, 2013).

Autonomia e desenvolvimento podem ser entendidos como elementos ideacionais, fatores presentes nas formulações de cada país e que permitiram a identificação de valores e desafios comuns, servindo como um primeiro eixo de contato para a cooperação. Tal como entendidos, não constituem explicações totais para a tônica cooperativa, sendo que em um contexto distinto poderiam até mesmo ter gerado uma situação de mais desconfiança e competição. Contudo, o binômio constituiu-se como impulsionador no processo de 
acercamento. A busca por autonomia e desenvolvimento forneceu bases para o delineamento das políticas de Argentina e Brasil na área nuclear durante boa parte da segunda metade do século XX.

Autonomia e desenvolvimento são termos constantemente citados no histórico dos programas e atividades dos dois países em matéria nuclear, aparecendo também no processo de aproximação bilateral. Mais ainda, referem-se a ideias que servem como base da cooperação na área. No caso de desenvolvimento, como uma concepção de melhoria das condições do país em termos gerais, embora por vezes seja empregado de forma semanticamente esvaziada. Do ponto de vista da discussão sobre o que se almeja com os esforços em tecnologia, a busca por autonomia se refere a duas questões em grande medida relacionadas: uma visão de autonomia tecnológica, a perspectiva de se desenvolver tecnologia avançada por meios próprios, fomentando a capacitação de mão-de-obra e a participação da indústria local; a perspectiva da autonomia política, a necessidade de garantir a capacidade de estabelecer políticas e projetos sem sofrer constrangimentos externos que impeçam a concretização dos planos e objetivos firmados.

A linha argumentativa geral deste artigo está embasada na centralidade das ideias. Propõe-se que as ideias de autonomia e desenvolvimento inspiraram e impulsionaram a cooperação no campo nuclear entre a Argentina e o Brasil. Graças a esta díade ideacional - autonomia e desenvolvimento - os dois países convergiram em alguns interesses, que geraram determinadas instrumentalidades e que apontaram para certo nível de identidade. Tais pontos não significam propor que todas as iniciativas dos dois países na área nuclear foram efetivamente guiadas por princípios de autonomia e desenvolvimento e que não existiram contradições, ou mesmo que havia uma concepção convergente de seus significados.

As ideias importam. Tal afirmação constitui o resumo de um dos aspectos centrais da chamada 'virada sociológica' que as Relações Internacionais experimentaram e que atualmente desfruta de um lugar consolidado nos debates teóricos da disciplina. A perspectiva encontra-se presente especialmente nos autores que se utilizam de uma abordagem construtivista. Para Kowert e Legro (1996), não se pode ignorar o impacto de fatores não-materiais. A importância dos elementos ideacionais pode ser observada nos efeitos de normas para as relações e para o ambiente da política internacional. Tais efeitos ocorrem em três dimensões: impacto sobre quais são os interesses dos atores; repercussão sobre os instrumentos considerados válidos para perseguir tais interesses; impactos em outras normas e nas identidades dos próprios atores (KOWERT; LEGRO, 1996).

As considerações sobre os efeitos das normas - interesses, instrumentalidade e identidades - e seu caráter ontológico também podem ser aplicadas a elementos ideacionais de forma geral e ajudam a explicar a sua relevância. Ao considerar o impacto dos fatores ideacionais para a Análise de Política Externa, Jesus (2009) afirma que as ideias podem constituir os interesses dos Estados, regular seus comportamentos e compor suas identidades, sendo fatores endógenos aos processos de interação. Trata-se de construção social, de uma coconstituição entre agente e estrutura em que interesses e identidades não são dados e fatores ideacionais importam. Está em pauta o ambiente cultural das interações, e não somente seus constrangimentos materiais. Ao considerarem a elaboração de políticas de segurança dos Estados, Jepperson, Wendt e Katzenstein (1996) consideram a camada das instituições formais ou regimes; a camada de uma cultura política mundial e a camada de padrões de amizade e inimizade entre os Estados. Apresenta-se assim o contexto mais amplo que 
elementos não-materiais auxiliam a desenhar as interações entre os atores, alinhando-se à concepção de Wendt (2000) de que ideias são constitutivas de interesses.

Para os fins do presente artigo, não carece trazer todo o marco teórico central para a discussão de aspectos ideacionais, nem mapear o estado da arte desses estudos. Procura-se ressaltar que aspectos ideacionais são fatores importantes para a análise de temas da política internacional, pois têm influência sobre os atores, suas relações e o ambiente social mais amplo. Todavia, o foco de análise não se ocupa de tratar especificamente dos atores, mas sim das ideias de autonomia e desenvolvimento presentes nas relações entre eles.

No artigo, são utilizadas fontes secundárias e primárias sobre o tema, incluindo acordos e declarações referentes à questão nuclear, além de documentos do ministério de Relações Exteriores e Culto na Argentina, consultados diretamente no Arquivo Histórico da Chancelaria. O delineamento metodológico completa-se com uma abordagem histórica do processo de cooperação na área nuclear entre a Argentina e o Brasil.

Apresenta-se, de início, uma breve síntese acerca do debate sobre autonomia e desenvolvimento nos anos 1950 e 1960, no sentido de conferir contextualidade ideacional às ações depreendidas pelos dois países. Na sequência, a discussão sobre autonomia nos programas nucleares de Argentina e Brasil, seguido pela associação entre tecnologia nuclear e desenvolvimento. Posteriormente, exploram-se estes dois elementos na aproximação bilateral e como se constituíram em fatores para identificação de soluções conjuntas.

\section{Autonomia como proposta em par com o desenvolvimento}

Interessa indicar alguns pontos centrais acerca dos debates latino-americanos sobre desenvolvimento e autonomia. Nos anos 1950 e 1960, o apelo pelo desenvolvimento tornou-se uma das tônicas das ciências sociais na América Latina. Com variações significativas, o tema mobilizou acadêmicos formuladores de políticas e constituiu-se em agenda para variadas postulações de planos de governo e perspectivas de construção nacional. Ainda que o quadro internacional se caracterizasse pelo fortalecimento da bipolaridade, que funcionava como força constrangedora do sistema internacional, possibilidades alternativas abriam-se aos países periféricos em relação aos dois centros de poder.

Essas possibilidades forneceram às ciências sociais na década de 1950 boa dose de otimismo. Santos (1976) confere essa aura ao considerar o desenvolvimento como uma aventura dos povos, mas que obriga a uma perspectiva histórica e não formal. A análise histórica e o reconhecimento da frincha entre os dois polos inspiravam pensadores a considerarem novas possibilidades de inserção internacional.

Em síntese, pode-se considerar que a demanda pelo desenvolvimento provinha de duas matrizes diferenciadas. Em uma, a ausência de recursos para investimento apontava para a necessidade de aporte financeiro dos países desenvolvidos, que se concentrava basicamente nos Estados Unidos. Daí a conclusão de que seria preciso ajustar-se às condicionantes estadunidenses, flexibilizar normas aderentes aos mercados e fortalecer as vocações nacionais e regionais ligadas ao setor primário da economia. Em outro diapasão, autores que postulavam pelo fortalecimento da indústria local, via a substituição das importações, entre outros mecanismos, e que defendiam, como parte relevante das ações, uma postura de relativo distanciamento dos Estados Unidos. 
O embate entre os dois grupos foi intenso e pode ser claramente observado naquele período na Argentina e no Brasil. A atenção será devotada ao segundo grupo. A tônica do desenvolvimento, neste caso, estava assentada na busca por maior autonomia, o anverso - não absoluto - da dependência para o pensamento de base estruturalista vigente na América Latina. Este pensamento seria o ponto de partida de análises e propostas como a de Hélio Jaguaribe, no Brasil, e de Juan Carlos Puig, na Argentina, autores da denominada Escola Doutrinária sobre a Autonomia Latino-Americana (GRANATO, 2014).

Para Jaguaribe (1976), era preciso reconhecer o quadro geral relativo a tendências estruturais da América Latina, caracterizado pela estagnação econômica, política, social e cultural, que fomentava uma marginalidade em tríplice aspecto: marginalidade crescente dentro da região; marginalidade crescente de toda a região em relação às regiões e países mais desenvolvidos; e marginalidade, em todos os países da região, dos setores primários e terciário em relação ao secundário. A marginalidade vinha acompanhada pela desnacionalização dos setores estratégicos da economia; cultural, mediante o estabelecimento de uma dependência científico-tecnológica com caráter crescente e acumulativo; e político-militar, mediante o crescente controle dos países da região por dispositivos político-militares, cuja concepção de mundo e interesses corporativos se fundam na liderança dos Estados Unidos.

Jaguaribe (1976) sugeria três possibilidades de saída: dependência, autonomia e revolução. Descartava a primeira e a terceira, por razões diferenciadas, e defendia o caminho da autonomia como a saída para os países latino-americanos, de per se, e da região, como um todo. Considerava pertinente um modelo de autonomia representacional, que englobaria um modelo de desenvolvimento cultural, social, econômico e político dos países como sociedades nacionais e de outro, pela integração dessas nações. Para sua concretização, seria necessário superar as relações de dependência em relação aos EUA, que seriam de ordem científico-tecnológica, econômico-financeira e administrativa, o que exigiria a adoção de novas políticas e normas concernentes a invenções e patentes e capitais estrangeiros.

A conquista da autonomia resulta de duas condições básicas: a viabilidade nacional e a permissibilidade internacional. A primeira depende, em certo momento histórico, de um mínimo crítico de recursos humanos e naturais (JAGUARIBE, 1986) que repercute condicionalidades de exigência tecnológica de cada época. Há uma ênfase no grau de coesão interna como atributo necessário da viabilidade nacional, destacando a relevância atribuída pelos atores ao desenvolvimento e à busca de autonomia. A permissibilidade internacional diz respeito “à medida em que, dada a situação geopolítica de um país e suas relações internacionais, esse país disponha de condições para neutralizar o risco proveniente de terceiros países, dotados de suficiente capacidade para exercer sobre ele formas eficazes de coação." (JAGUARIBE, 1986, p. 41).

Jaguaribe foi um dos mais consistentes defensores de uma abordagem autonomizante e multidimensional do nacionalismo, este último de caráter instrumental (LESSA, 2013). As formulações do autor permitem uma triangulação com Juan Carlos Puig, que tratou, de forma singular e própria, o nacionalismo, a autonomia, o desenvolvimento e a integração regional. Para Puig (1986), quanto mais autônomo é um ente, serão maiores as possibilidades para desenvolver-se de acordo com as suas próprias 
volições. Ou seja, a autonomia outorga a possibilidade de adotar políticas mais justas e equilibradas, enquanto a subordinação cerceia, ou ao menos reduz, essa possibilidade, na medida em que facilita ao dominante impor seus próprios critérios ao que está subordinado. Essa indicação remete ao conceito de autonomia formulado por Jaguaribe e acolhido neste trabalho: "a existência de condições que permitam a livre tomada de decisões como a resolução deliberada de exercitar tais condições" (JAGUARIBE, 1976, p. 52). Em direção similar, Puig (1986) definiu a autonomia como a capacidade de uma nação para optar, decidir e trabalhar por si mesma. Em síntese, o termo autonomia remete à ideia de ampliação das margens de atuação, ou de escolha, do Estado, tendo em conta a percepção das condições do sistema doméstico e internacional em um determinado período (VIGEVANI; RAMANZINI, 2014).

Convém ressaltar dois pontos. O primeiro é que um desenvolvimento autônomo e, especificamente, de integração da América Latina consistiria em processos cujas decisões relevantes seriam tomadas por atores e agências latino-americanas, baseadas em seus próprios interesses, conforme a sua própria perspectiva e através de suas livres decisões (JAGUARIBE, 1973 apud GRANATO, 2014) e que a integração regional é uma forma de ampliação da autonomia. Um segundo aspecto é que a integração poderia ocorrer por similitudes, ou porque atores possuem condições similares, ou porque compartilham valores similares. No caso da América Latina um dos valores seria exatamente a autonomia (PUIG, 1986).

O jogo da busca da autonomia, confrontando interesses de atores nacionais e internacionais, ultrapassa uma linearidade de um jogo de soma zero. Assim fosse, as possibilidades de cooperação seriam nulas ou mínimas (RUIZ; SIMONOFF, 2017). De fato, Jaguaribe chegou a propor uma autonomia periférica, condição estabelecida pela análise das condições concretas de cada país no processo de busca da autonomia (JAGUARIBE, 1973 apud RUIZ; SIMONOFF, 2017).

O tema não é aqui discutido com base em tipologias propostas por diversos autores, como autonomia pela participação (FONSECA JUNIOR, 1996); autonomia pela diversificação (VIGEVANI; CEPALUNI, 2007) ou desejo pela autonomia (PINHEIRO, 2000). O relevante para os propósitos das ideias de autonomia e desenvolvimento é considerar as demarcações estabelecidas pelos atores na conformação de projetos autonômicos, como a cooperação nuclear. Ademais, tais adjetivações fornecem material para outra análise, inclusive a que postula a identificação de similitudes em fases muito diferenciadas de um ponto de vista político e ideológico, sendo que o caráter autonomista é muito mais excepcional do que recorrente (MILANI; PINHEIRO; DE LIMA, 2017). Relevante para este artigo é a consideração dos autores de que exatamente a exceção é a política nuclear brasileira desde 1967.

As ideias sobre autonomia e desenvolvimento coincidem com as definições sobre a questão nuclear na Argentina e no Brasil e fornecem elementos substantivos para se compreender a lógica da aproximação.

\section{Autonomia e desenvolvimento como referências nacionais no campo nuclear ${ }^{3}$}

A ideia de autonomia esteve presente tanto na Argentina, quanto no Brasil, no decorrer das atividades em matéria atômica, pois havia a perspectiva de um desenvolvimento autônomo, tentando evitar a

\footnotetext{
${ }^{3}$ Essa discussão foi desenvolvida na dissertação de mestrado de Luiza Elena Januário, realizada com bolsa CAPES, defendida no Programa de Pós-Graduação em Relações Internacionais San Tiago Dantas em fevereiro de 2017 e orientada por Samuel Alves Soares.
} 
dependência estrangeira e promover recursos e iniciativas nacionais. Contudo, isso não significa que não ocorreram divergências sobre a pertinência dessa orientação e nem que todos os esforços empreendidos corroboraram para essa linha, ou mesmo que a autonomia deva ser entendida como uma condição absoluta. Porém, esforços no sentido de promover a autonomia tecnológica podem produzir ganhos e consagrar uma visão de mundo relevante, pois, como afirma Adler (1988, p. 60), “a autonomia tecnológica pode nunca ser atingida, mas no processo de se tentar obtê-la, [...] atores podem ajudar a trazer desenvolvimento tecnológico suficiente para mudar a performance industrial e atingir objetivos econômicos, sociais e de segurança nacional".

Um debate que remete ao peso da questão da autonomia relaciona-se à escolha de reatores e combustíveis, quando decidida a construção de centrais nucleares. Havia duas opções: reatores de urânio enriquecido e água leve e reatores de urânio natural e água pesada. O primeiro tipo dominava o mercado mundial, apresentando as vantagens de ser uma tecnologia consolidada e mais econômica. Porém, existia a questão de uma contínua dependência externa para o fornecimento do urânio enriquecido. Por sua vez, os reatores de urânio natural eram mais caros, mas não estavam associados a essa dependência do material enriquecido. A noção de autonomia esteve presente nesse debate e nessa decisão. Na Argentina, teve grande destaque o argumento de que a compra de reatores de urânio enriquecido deixaria o país muito dependente dos EUA, sendo realizada então a escolha por reatores de urânio natural (OLIVEIRA, 1996). No Brasil, as decisões favoreceram a compra de reatores de urânio enriquecido a partir do entendimento que tal escolha seria mais conveniente para os interesses do país no momento, especialmente no sentido de garantir uma fonte suplementar de energia elétrica em curto prazo (MOTTA, 2010). Pinguelli Rosa (2006) aponta a existência de um paradoxo entre uma retórica política altiva, de busca de autonomia, e uma prática submissa, a opção de urânio enriquecido que implica na importação desse combustível.

Outros episódios no histórico dos programas nucleares dos dois países também ilustram o debate sobre autonomia. No caso da Argentina, desde 1952 foram construídos laboratórios e empreendidos esforços para formar um corpo de especialistas. Sábato (1968) destaca que a formação adequada de um quadro próprio de cientistas e técnicos constituiu uma preocupação central da Comissão Nacional de Energia Atômica (CNEA), que centralizava as atividades nucleares do país, reforçando, a preocupação em dotar o país de condições de autonomia neste campo.

Além disso, em 1958, foi inaugurado, no Centro Atômico de Constituyentes, o primeiro reator experimental da América Latina, o RA-1, construído inteiramente na Argentina. Sábato (1968) considera que a decisão de construir o reator foi importante não só para servir como treinamento e pesquisa, mas também para desenvolver capacidade própria em engenharia nuclear. A noção da importância deste fator continuou com o processo de Reorganização Nacional (1976-1983). Em 1979, foi aprovado o Plano Nuclear Argentino que visava a autossuficiência em recursos humanos, equipamentos e tecnologia, o domínio completo do ciclo do urânio enriquecido e a qualidade de fornecedor nuclear confiável (ORSOLINI, 1984). Bertoni (1984) ressalta a perseguição de promoção industrial - a participação local nas instalações nucleares - como um traço importante e contínuo das ações argentinas. 
Hurtado (2012, p. 165) argumenta que se constituiu na Argentina uma cultura nuclear,

um campo de práticas portadoras de representações, crenças, valores e projetos nos quais intervêm múltiplos setores e tipologias de atores [...] que associaram um projeto de desenvolvimento tecnológico a componentes de política nacional, como a busca da autonomia tecnológica - entendida como a capacidade do país para alcançar objetivos tecnológicos sem interferências ou restrições externas -, o impulso do processo de industrialização e da liderança científico-tecnológica regional [...].

Tal configuração está relacionada a entendimentos intersubjetivos sobre a área que permitiram certa coesão das iniciativas ao longo do tempo. Está em destaque não apenas um fim exclusivamente técnico, mas principalmente uma determinada visão de mundo - o que perpassa a identificação pelos atores de seus interesses, de seus princípios e dos meios apropriados para alcançar seus objetivos, bem como das variáveis externas e dos desafios para seus projetos.

Oelsner (2005) destaca que a política nuclear argentina de modo geral foi conduzida de forma coerente e contínua. Bertoni (1984) argumenta que a coerência e continuidade das iniciativas na área nuclear asseguradas pela CNEA, a despeito de todas as mudanças políticas ocorridas no país, constituíram um elemento central para os sucessos alcançados. Pode-se notar que a procura de algum grau de autonomia é uma constante de tal política, o que pode ser identificada na escolha e reafirmação do urânio natural como combustível e encontra-se relacionada aos objetivos de capacitação de mão de obra própria e construção de seus equipamentos.

No caso do Brasil, a busca por autonomia constituiu-se em impulso fundamental para as ações do almirante Álvaro Alberto Motta e Silva, o criador e primeiro presidente do Conselho Nacional de Pesquisa (CNPq). O almirante defendia o princípio das 'compensações específicas', ao estabelecer que exportações de minerais atômicos deveriam ter como contraponto transferência de tecnologia útil ao desenvolvimento nuclear do país (CAMARGO, 2006), em contraposição à situação em que o Brasil se firmava como fornecedor de minerais na área nuclear sem compensações.

No decorrer dos anos 1950, evidenciou-se o debate entre uma visão autonomista e perspectivas que defendiam uma maior aproximação com os EUA. Em 1954, fortaleceu-se a essa cooperação no âmbito nuclear, o que levou à exoneração de Álvaro Alberto da presidência do CNPq. Porém, em 1956, foi realizada uma Comissão Parlamentar de Inquérito (CPI) para averiguar denúncias de que a política nuclear do governo anterior atentava contra os interesses nacionais, e teria ocorrido um cooptação pelos Estados Unidos (PEREIRA, 2013). Segundo Pereira (2013), houve a irrupção de uma polarização entre aqueles que defendiam retomar a visão autonomista de Álvaro Alberto e aqueles que consideravam a aproximação com os EUA como única forma de avançar no tópico da energia nuclear. De acordo com Soares de Lima (2013), o final dos anos 1940 e início dos anos 1950 foram marcados por essa divisão entre setores que defendiam um programa independente e outros que argumentavam que só seria possível obter acesso à energia nuclear se o Brasil se consolidasse como um aliado dos EUA. A autora aponta que, entre os primeiros, havia duas visões: uma autossuficiente, contrária à importação de tecnologia, e outra auto dependente, que não se opunha à cooperação internacional desde que o controle da tecnologia fosse brasileiro. 
Um marco importante das atividades nucleares brasileiras é o programa 'paralelo' ou 'autônomo', um projeto nuclear secreto criado em 1979, coordenado pela Comissão Nacional de Energia Nuclear (CNEN) e implementado pelas três Forças Armadas. Esse programa não era submetido às salvaguardas internacionais e cada uma das Forças possuía seus próprios projetos. Barletta (1997) destaca que a ideia de autonomia teve um relevante peso nesse contexto, pois permitiu manter uma coesão mínima entre os diferentes setores envolvidos na iniciativa, que muitas vezes apresentavam motivações e objetivos distintos.

Nesse sentido, Barletta (1997) aponta que, para as Forças Armadas, o programa estava relacionado à possibilidade de aumentar o prestígio brasileiro no exterior e conquistar mais respeito para os militares no plano interno. Para a Marinha era a oportunidade de construção de um submarino com propulsão nuclear, enquanto setores minoritários na Força Aérea e na área de Inteligência mantinham expectativas de construção de dispositivos explosivos. Por fim, para cientistas civis, além do emprego em processo de tecnologia de ponta, o envolvimento no programa era visto como um serviço patriótico para a tecnologia nacional e para a produção de energia. O autor salienta que, além de consenso, a ideia de autonomia possibilitou que diferentes atores identificassem como a tecnologia afetaria seus interesses e quais seriam as alternativas políticas, servindo também como um instrumento retórico para que as Forças Armadas justificassem seu envolvimento no desenvolvimento nuclear.

De qualquer modo, uma orientação de autonomia tecnológica guiou grande parte das atividades brasileiras no setor nuclear, ainda que muitas decisões não convirjam com esta perspectiva. Nesse sentido, aponta-se a já citada escolha de reatores a urânio enriquecido e o fim do Grupo do Tório. Criado no final de 1965, o Grupo tinha a atribuição de analisar as possibilidades de usar o tório no programa nuclear para a geração de energia, existindo estudos para a construção de um reator utilizando o material. O Grupo ganhou notoriedade especialmente junto a setores nacionalistas (CAMARGO, 2006). Porém, o Grupo do Tório foi desmantelado com a decisão do governo Médici de adotar reatores de água leve.

Outro aspecto que aponta tensões e contradições no programa nuclear brasileiro pode ser encontrado no Acordo de 1975 com a Alemanha. Baseado em um esforço de buscar novos parceiros na área nuclear, o Acordo era amplo, visava a instalação de um parque de indústrias nucleares e a obtenção da tecnologia do ciclo completo do combustível nuclear, sendo que esse último ponto ocorreria por um método ainda experimental, a jato-centrifugação. Carpes (2014) destaca como central o aspecto da transferência da tecnologia de enriquecimento de urânio, uma vez que estava associada à busca de autonomia. A escolha do parceiro ocorreu justamente pelas condições esperadas que surgiriam com o acordo no sentido do domínio completo do ciclo do urânio (RONCONI et al., 2015).

Entretanto, ocorreram diversas dificuldades para a implementação, entre as quais a insatisfação da comunidade científica brasileira (OELSNER, 2005), não consultada durante o processo negociador e, entre suas críticas, encontrava-se descrença em relação ao método de jato-centrifugação e às reais possibilidades de transferência de tecnologia de forma geral, bem como o fato de o governo não estar fomentando a criação de tecnologia própria (CHAVES, 2014). Porém, a oposição não era ao desenvolvimento da energia nuclear em si, como acontecia em muitos países desenvolvidos na época, mas sim ao fato de que o governo não estava 
sendo realmente assertivo na busca de independência (CAMERON, 2018). Pode-se considerar que o Acordo mantinha uma das facetas de busca de autonomia, qual seja, a diversificação de parceiros. Por outro lado, o Acordo não atendeu a outro requisito, o de desenvolvimento de capacidades nacionais em termos tecnológicos.

Dessarte, a questão da autonomia tecnológica pode ser entendida também como um eixo entre a configuração interna dos programas nucleares dos dois países e o posicionamento externo adotado por eles. Internamente, há a caracterização da tecnologia nuclear como um setor importante e relacionado às possibilidades de desenvolvimento e melhora de condições dos países. No plano externo, há a contraposição às iniciativas que possam restringir o avanço dos programas e à formação de um regime internacional entendido como discriminatório, bem como a resistência às pressões de outros países, especialmente dos EUA, no sentido de dificultar o desenvolvimento próprio na área nuclear.

Retomando-se a questão da autonomia nos dois países em governos civis e autoritários, observa-se um quadro em que o país é suscetível a pressões externas, que produzem dificuldades de monta para perseguir seu desenvolvimento econômico e social, mas que ainda assim mantém um caminho autonomista por meio do desenvolvimento tecnológico, exatamente como postulavam Jaguaribe e Puig. De modo similar, Diez (2016) afirma que no final dos anos 1960 e início dos anos 1970, a teoria da autonomia latino-americana reforçou a ideia de busca de autonomia na área nuclear, robustecendo a visão existente nas décadas de 1950 e 1960 de que o avanço nuclear estava relacionado a noções de progresso, modernização, prestígio e superioridade estratégica.

Camargo (2006, p. 172) afirma a visão da energia atômica como "uma espécie de trampolim para o futuro", uma opção tecnológica avançada com efeito multiplicador na economia, é fortemente relacionada ao pensamento do almirante Álvaro Alberto no Brasil. Pereira (2013) defende que, nesse período, havia a percepção de se tratar de um esforço amplo no sentido de capacitação científica, não se restringindo a um binômio formado por eletricidade e artefatos bélicos. Na Argentina a questão também aparece. Sábato (1968) apontava que era possível identificar três objetivos da política atômica argentina: dotar o país de capacidade própria de decisão no que tange à energia nuclear; criar infraestrutura científica e tecnológica com a finalidade de garantir o aproveitamento da energia nuclear; e contribuir para a modernização da sociedade argentina. Hurtado (2012) aponta que as atividades do país, desde o começo da década de 1950 até princípios dos anos 1990, tiveram uma orientação pragmática, sendo seu início impulsionado por um projeto de industrialização e a questão nuclear esteve sempre relacionada às noções de autonomia e modernização.

Um documento de 1986 da chancelaria argentina sobre o posicionamento do país, em termos de política nuclear, estabelece o desenvolvimento da capacidade industrial na área nuclear como um de seus objetivos centrais a partir da concepção de que as transformações tecnológicas teriam efeito em todo o sistema produtivo, servindo como motor de mudanças substantivas nas atividades industriais (ARGENTINA, 1986). A importância da questão do desenvolvimento, bem como sua conexão com o tema da autonomia, também pode ser constatada em esboço de discurso da delegação argentina em Conferência Geral do Organismo para a Proscrição de Armas Nucleares na América Latina e no Caribe (OPANAL) de 26 a 30 de abril de 1987. Assim, é afirmado que se o país busca 
alcançar e sustentar um grau de desenvolvimento que permita tomar decisões de maneira autônoma no campo energético. Em um mundo altamente tecnificado, não contar com bases tecnológicas próprias cria uma dependência que afeta o desenvolvimento econômico e social e atenta contra a possibilidade de adotar decisões (ARGENTINA, 1987, p. 11, tradução nossa).

Pode-se afirmar que autonomia e desenvolvimento constituem tanto um objetivo, quanto um valor. A busca por maior grau de desenvolvimento é constante entre os interesses desses Estados. As noções de desenvolvimento e autonomia podem ser consideradas como aspectos ideacionais das políticas nucleares de Argentina e Brasil.

\section{Ideias em ação: autonomia e desenvolvimento no campo nuclear entre Argentina e Brasil}

A associação entre energia nuclear, autonomia e desenvolvimento também foi importante para fundamentar a aproximação bilateral entre Argentina e Brasil. Tal relação constitui um dos elementos basilares das declarações conjuntas e acordos na área nuclear no decorrer da década de 1980. No Acordo de cooperação de 1980 foi inserido que "o desenvolvimento da energia nuclear para fins pacíficos constitui um elemento fundamental para promover o desenvolvimento social e econômico de seus povos” (ARGENTINA; BRASIL, 1980, p. 1). Além disso, no documento também foram ressaltados "os esforços que ambas as nações estão realizando a fim de incorporar a energia nuclear ao serviço de suas necessidades de desenvolvimento econômico e social" (ARGENTINA; BRASIL,1980, p. 1).

Em 1983, ocorreu na Argentina a transição de um regime burocrático-autoritário para um democrático, o que ocorreu no Brasil em 1985. Há perspectivas que apresentam tal transição como central para a aproximação bilateral, tanto em termos gerais (HURRELL, 1998), como na área nuclear (SOTOMAYOR, 2006). Nessa perspectiva, a cooperação está relacionada à necessidade de se consolidar o poder civil e restringir a força dos militares nos dois países. Também ganharam destaque argumentações que fundamentam a necessidade de um eixo estratégico Buenos Aires-Brasília, reaparecendo as propostas de Jaguaribe no sentido da pertinência da concertação política entre os países e de desenvolvimento conjunto de um pensamento crítico para sustentar decisões (PARADISO, 2005).

A afirmação do interesse dos dois países na paz e no desenvolvimento foi constantemente reiterada nas declarações a partir de então, bem como o reconhecimento dos impactos sociais e econômicos da tecnologia nuclear. Na Declaração Conjunta sobre Política Nuclear de 1985, foi assinalado que "a ciência e a tecnologia nucleares revestem-se, na vida de todo país moderno, de valor transcendente para promover significativamente seu desenvolvimento social e econômico" (ARGENTINA; BRASIL, 1985, p. 1).

A busca pela autonomia também esteve ligada à perspectiva de desenvolvimento em alguns desses documentos. Dessa forma, na Declaração de Iperó, em 1988, foi afirmada a “firme convicção na importância da energia nuclear para o desenvolvimento econômico e social de seus povos e reafirmam o direito inalienável de desenvolver, sem restrições, seus programas nucleares para fins pacíficos” (ARGENTINA; BRASIL, 1988, p. 1, grifos nossos). Além disso, o Protocolo No 17 - Cooperação Nuclear de 1986, já afirmava “o interesse comum de ampliar a autonomia de seus respectivos programas nucleares" (ARGENTINA; BRASIL, 1986, p. 1). 
Autonomia e desenvolvimento também se encontram relacionados a diferentes fatores que influenciaram a construção da cooperação bilateral na área nuclear. Diferentes interpretações podem ser formuladas unindo autonomia e desenvolvimento a aspectos que influenciaram o processo político. Um primeiro elemento a ser trabalhado se refere às pressões externas que os dois países sul-americanos sofreram durante grande parte da história de seus programas nucleares, devido à recusa em aderir ao regime global de não proliferação e ao fomento de iniciativas que visavam relativa autonomia e eram marcadas pela falta de transparência.

As discordâncias em relação ao Tratado de Tlatelolco eram pautadas pelo desejo dos países com os programas nucleares mais avançados da região de preservar possibilidades de desenvolvimento tecnológico, o que muitas vezes era associado à necessidade de se atingir algum nível de autonomia na área. Por sua vez, as negociações do Tratado de Não Proliferação Nuclear (TNP) sugerem que a ideia de autonomia se tornou um estímulo para a busca de resistência ao ímpeto das potências nucleares em impor restrições e barreiras ao desenvolvimento autônomo nesta área. Wrobel (2017) destaca que a colaboração argentino-brasileira foi em grande medida promovida por uma percepção comum acerca da natureza do regime de não proliferação.

Os dois países resistiram às pressões e obtiveram significativas conquistas tecnológicas, sendo um exemplo de destaque o enriquecimento de urânio, anunciado pela Argentina em 1983 e pelo Brasil em 1987. A identidade de países periféricos que almejam o desenvolvimento constituiu-se como um elemento que fundamentou a oposição às pressões. A relação entre desenvolvimento e autonomia auxilia a esclarecer ainda mais esse quadro, uma vez que as pressões eram muitas vezes concebidas como uma tentativa das potências de manter o status quo, configurando um obstáculo às iniciativas de desenvolvimento dos países periféricos. A procura por promover projetos autônomos pode ser vista como a resposta a essa tensão.

Autonomia e desenvolvimento foram aspectos centrais para uma concepção de que entendimentos bilaterais constituíram um elemento chave para a aproximação nuclear. A identificação de convergências no que se refere às atividades nucleares de Argentina e Brasil foi um fator importante para a aproximação dos dois países em matéria nuclear, o que, por sua vez, constituiu uma forma de impulsionar a cooperação em termos mais amplos. Nessa perspectiva, a superação de pontos de tensão do relacionamento bilateral e a identificação de valores e desafios comuns fomentaram o ensejo da cooperação.

Entre os desafios comuns encontram-se justamente as pressões sofridas pelos dois países nos intentos de promover projetos autônomos na área sensível. Há perspectivas que ressaltam que as pressões não atingiram os efeitos desejados e fortaleceram a resistência (REDICK, 1995; HYMANS, 2001), sendo estimulada uma lógica de identificação entre atores de Argentina e Brasil (CAMILIÓN, 2000; MALLEA, 2012).

A aproximação bilateral que ocorreu especialmente a partir de meados da década de 1980, traz questões de um contexto específico, marcado por uma situação política delicada e pelo aumento de dificuldades econômicas, sendo possível citar que a Guerra das Malvinas em 1982 constituiu um episódio traumático para a Argentina, e em que o Brasil adotou uma 'neutralidade imperfeita', favorável ao seu vizinho (BANDEIRA, 2012). Apesar das dificuldades encontradas nesse período, pode-se apontar que a associação entre energia nuclear, desenvolvimento e autonomia, elaborada anteriormente com a criação e o progresso dos programas nucleares, forneceu as bases para os esforços cooperativos. Tratava-se de concepções e 
objetivos que podiam ser identificados, em menor ou maior medida, nas políticas dos dois países e produziram gradualmente uma identificação que, em um determinado contexto, impulsionou a busca de diálogo e ações comuns.

Ressalta-se o papel dos cientistas nesse processo, tanto no sentido de promover, com maior ou menor sucesso, a associação entre autonomia, desenvolvimento e tecnologia nuclear no interior dos países, quanto no de incentivar a troca de informações e a aproximação estatal, além do papel instrumental na criação dos mecanismos de controle e confiança mútua. Há pesquisas que indicam a formação de uma comunidade epistêmica na área nuclear por cientistas e autoridades de Argentina e Brasil (KUTCHESFAHANI, 2010; 2016).

Autonomia e desenvolvimento não são metas exclusivamente pragmáticas que serviram como impulso para a aproximação, mas bases que refletem uma certa visão de mundo e permitiram a identificação de similaridades que serviram de alicerce para a ação de distintos atores. Nos anos 1990, a ideia de autonomia perde ímpeto nas iniciativas de Argentina e Brasil, dando lugar ao aprofundamento da busca por transparência (VARGAS, 1997). Há interpretações alternativas que valorizam justamente as transformações sofridas na década de 1990, no contexto do neoliberalismo econômico em que os governos brasileiro e argentino adotaram medidas que estimularam a mudança de postura do Brasil e Argentina frente ao regime de não proliferação e à cooperação bilateral. Solingen (1994) argumenta que quando coalizões formadas por atores que advogam pela liberalização ganham proeminência em um país, há uma tendência à adesão de uma postura mais branda e cooperativa no que se refere à política nuclear. Isso ocorre porque tais coalizões consideram que transcender uma situação de ambiguidade a respeito dos programas apresenta-se de forma favorável aos seus interesses, uma vez que estes estão alinhados a estratégias de internacionalização e maximização de lucros no mercado global.

Ideias e entendimentos intersubjetivos têm efeitos constitutivos na realidade social e na sua evolução (ADLER, 2002), ou seja, crenças, entendimentos e expectativas fazem parte do processo de atribuição de significados sobre a realidade social e são indissociáveis da análise de uma determinada situação e identificação de cursos de ação possíveis, fundamentando não só a escolha de determinados caminhos, mas também como os atores veem a si próprios e aos seus pares em um contexto. Tanto ideias como questões materiais constituem interesses. Dessa forma, ideias não são somente regras ou mapas do caminho, mas moldam os próprios atores em suas ações no mundo político (FARRELL, 2002). É nesse sentido que se postula que autonomia e desenvolvimento constituíram ideias que contribuíram para a criação de bases para a aproximação entre Argentina e Brasil ao fornecerem pontos de convergência de valores e terreno para a percepção de dificuldades comuns.

\section{Considerações finais}

No singular mosaico das relações entre Argentina e Brasil, as ideias de autonomia e desenvolvimento têm destaque. Constituindo tanto objetivos, quanto valores, estiveram presentes nas deliberações acerca dos programas nucleares. Tais questões não se referem somente à área atômica, mas são também constitutivas das identidades. A associação entre energia nuclear e desenvolvimento e a busca por autonomia 
representaram pontos de identificação entre Argentina e Brasil que serviram para solidificar bases para a construção da cooperação. Os dois países sofreram pressões externas devido à ambição de autonomia, sendo que essa fundamentou a oposição similar ao Tratado de Não Proliferação Nuclear e levou a demonstrações de solidariedade. Além disso, como países periféricos, Argentina e Brasil enfrentavam desafios comuns para a produção de tecnologia avançada com vistas ao desenvolvimento nacional.

A díade autonomia e desenvolvimento forneceu um eixo comum para a aproximação entre os dois países e para a percepção que estavam em posições semelhantes e que esforços cooperativos seriam proveitosos. As duas ideias, de alguma forma, guiaram a cooperação nuclear estabelecida, mas não significa que constituíssem a finalidade de tal movimento. As ideias serviram como incentivo para buscar algo além da situação de desconfiança que predominava. A desconfiança passou a ser descontruída para gerar um quadro novo, reafirmando o caráter ideacional de autonomia e desenvolvimento nesse processo.

À indagação mais ampla do que produz a cooperação entre países, podem ser alocadas explicações de caráter pragmático e utilitarista, ao gosto das concepções institucionalistas. Constituem propulsores importantes, e seu embasamento finalístico é que os atores são dotados de uma racionalidade impermista. Em outra angulação, podem ser apontados os cálculos estratégicos dos atores, os quais vislumbram condições para firmar alianças e ampliar sua própria segurança ao evitar conflitos sempre que possível. São explicações correntes no campo nuclear e possivelmente as mais privilegiadas.

Sem descurar a validade de interpretações desse teor, postula-se que os diagnósticos e ações de atores, estatais ou não, estão vinculados ao modo como atribuem significado a estas ações em um quadro intersubjetivo mais amplo, e que contempla a visão do Outro e de si mesmo. Aspectos ideacionais não implicam necessariamente em cooperação, bem ao contrário, podem produzir hostilidades em graus variados. Entretanto, neste trabalho o intento foi inventariar situações de cooperação. Entre Argentina e Brasil identifica-se um elemento ideacional centrado na busca por autonomia e desenvolvimento, que no campo nuclear tem produzido condições para a cooperação. Sem ilusões de irreversibilidade, valores e princípios similares configuram um laço que mantém antigos contendores impulsionados a produzirem condições para o exercício da autonomia e a construção de fundamentos para o seu desenvolvimento.

Configura-se um quadro ideacional consistente no sentido de amparar a cooperação em uma área de extremada sensibilidade. As ideias de autonomia e desenvolvimento conduziram a uma convergência de interesses, fornecendo as condições de estabelecimento de instrumentalidades consideradas válidas para garantir tais interesses e, por fim, repercutiram, embora de forma discreta, nas identidades dos dois países. Este processo foi se constituindo com acentuada natureza ideacional, e permitiu que entre a Argentina e o Brasil se estabelecesse um nível de cooperação na área nuclear singular e inusitado.

\section{REFERÊNCIAS}

ADLER, Emanuel. State Institutions, Ideology, and Autonomous Technological Development: Computers and Nuclear Energy in Argentina and Brazil. Latin American Research Review, v. 23, n.2, p. 59-90, 1988. 
ADLER, Emanuel. Constructivism and International Relations. In: CARLSNAES, W.; RISSE, T.; SIMMONS, B. (orgs.) Handbook of International Relations. London: Sage, 2002.

ARGENTINA. Ministerio de Relaciones Exteriores y Culto. [Política Nuclear Argentina], 1986. Archivo de Chancillería, serie 56 - Dirección de Asuntos Nucleares, s. topográfica 72.

ARGENTINA. Ministerio de Relaciones Exteriores y Culto. Programa Provisional OPANAL, 1987. Archivo de Chancillería, serie 56 - Dirección de Asuntos Nucleares, s. topográfica 72.

ARGENTINA; BRASIL. Acordo de cooperação entre o governo da República Federativa do Brasil e o governo da República Argentina para o desenvolvimento e a aplicação dos usos exclusivamente pacíficos da energia nuclear. Buenos Aires, 17 maio 1980. Disponível em: <http://www.abacc.org.br/wp-content/uploads/2015/09/Acordo-de-Coopera\%C3\%A7\%C3\%A3oentre-Brasil-e-Argentina-para-Usos-Pac\%C3\%ADficos-da-Energia-Nuclear.pdf $>$. Acesso em 3 maio 2016.

ARGENTINA; BRASIL. Declaração Conjunta sobre Política Nuclear, Foz do Iguaçu, 30 novembro 1985. Disponível em: <http://www.abacc.org.br/wpcontent/uploads/2015/09/Declara\%C3\%A7\% C3\%A3oconjunta-sobre-Pol\%C3\%ADtica-Nuclear-portugu\%C3\%AAs.pdf >. Acesso em 30 jun. 2015.

ARGENTINA; BRASIL. Declaração de Iperó, 8 abril 1988. Disponível em: <http://www.abacc.org.br/wpcontent/uploads/2015/09/Declara\%C3\%A7\%C3\%A3o-de-Iper\%C3\%B3 Acesso em 30 jun. 2015.

ARGENTINA; BRASIL. Protocolo No 17 - Cooperação Nuclear. Brasília, 10 dezembro 1986. Disponível em: <http://www.abacc.org.br/wp-content/uploads/2015/09/Protocolo-n\%C2\%BA-17portugu\%C3\%AAs.pdf >. Acesso em 12 mar. 2016.

BANDEIRA, Luiz Alberto Moniz. Guerra das Malvinas: petróleo e geopolítica. Revista Espaço Acadêmico, n. 132, maio 2012.

BARLETTA, Michael. The military nuclear program in Brazil. Center for International Security and Arms Control, Stanford University, 1997.

BERTONI, Jorge A. O plano nuclear argentino. Política e Estratégia, v. 2, n. 4, p. 512-17, 1984.

CAMARGO, Guilherme. $\mathbf{O}$ fogo dos deuses: uma história da energia nuclear. Rio de Janeiro: Contraponto, 2006.

CAMARGO, Sonia. Os novos amigos: Brasil e Argentina atravessam a ponte. Contexto Internacional, v. 2, n. 2, p. 63-80, 1985.

CAMERON, James. Technology, politics, and development: domestic criticism of the 1975 Brazilian-West Germany nuclear agreement. Rev. Bras. Polít. Int., v. 61, n. 2, 2018.

CAMILIÓN, Oscar. Memorias políticas. Buenos Aires: Planeta, 2000.

CARASALES, Julio C. The Argentine-Brazilian Nuclear Rapprochement. The Nonproliferation Review, v. 2, n.3, p.39-48, 1995.

CARPES, Mariana Montez. From breadcrumbs to threads of wool: Building a neoclassical realist approach for the study of regional power nuclear choices. PhD Dissertation, University of Hamburg and GIGA German Institute of Global and Area Studies, Hamburg, 2014.

CHAVES, Rodrigo Morais. O Programa Nuclear e a Construção da Democracia: Análise da Oposição ao Programa Nuclear Brasileiro (1975-1990). Dissertação de mestrado, Fundação Getulio Vargas CPDOC, Rio de Janeiro, 2014. 
DIEZ, Eduardo. Cooperación nuclear y especial. El caso argentino-brasileño: de la competencia a la colaboración. Perspectivas Revista de Ciencias Sociales, n. 2, jul.-dec. 2016.

FARRELL, Theo. Constructivism Security Studies: portrait of a research program. The International Studies Review, v. 4, n. 1, p. 49-72, 2002.

FONSECA JÚNIOR, Gelson. A legitimidade e outras questões internacionais. Poder e ética entre as nações. São Paulo: Paz e Terra, 1996.

GRANATO, Leonardo. A autonomia como vetor de ação externa e da integração na América do Sul: postulações teóricas. Oikos, v. 13, n. 2, p. 78-90, 2014.

HYMANS, J. E. C. Of Gauchos and Gringos: Why Argentina never wanted the Bomb, and Why the United States Thought it did. Security Studies, v. 10, n. 3, 2001.

HURRELL, Andrew. Security in Latin America. International Affairs, v. 74, n. 3, 1998.

HURTADO, Diego. Cultura tecnológico-política sectorial en el contexto semiperiférico: el desarrollo nuclear en la Argentina (1945-1994). Revista CTS 7 v. 21, p. 163-92, 2012.

JAGUARIBE, Helio. Dependência e autonomia na América Latina. In: JAGUARIBE, Helio; FERRER, Aldo; WIONCZEK, Miguel S.; SANTOS, Theotonio dos. Dependência político-econômica da América Latina. São Paulo: Loyola, 1976.

JAGUARIBE, Helio. O novo cenário internacional: conjunto de estudos. Rio de Janeiro: Guanabara, 1986.

JEPPERSON, Ronald L; WENDT, Alexander; KATZENSTEIN, Peter J. Norms, Identity, and Culture in National Security. In: KATZENSTEIN, Peter J. (org.). The Culture of National Security: Norms and Identity in World Politics. Nova York: Columbia University Press, 1996.

JESUS, Diego Santos Vieira de. Da redução da incerteza estratégica à perpetuação da exclusão: a relevância dos fatores ideacionais na Análise de Política Externa. Contexto Internacional, v. 31, n. 3, p. 50334, 2009.

KOWERT, Paul; LEGRO, Jeffrey. Norms, Identity, and Their Limits: A Theoretical Reprise. In: KATZENSTEIN, Peter J. (org.). The Culture of National Security: Norms and Identity in World Politics. Nova York: Columbia University Press, 1996.

KUTCHESFAHANI, Sara Z. The politics of the bomb: Exploring the role of epistemic communities in nuclear non-proliferation outcomes. Tese de doutorado, UCL, Londres, 2010.

KUTCHESFAHANI, Sara Z. Celebrating ABACC's $25^{\text {th }}$ year anniversary: a reflective piece on its creation. In: CANTO, Odilon Antonio Marcuzzo do. (org.) O modelo ABACC: um marco no desenvolvimento das relações entre Brasil e Argentina. Santa Maria: Ed. UFSM, 2016.

LESSA, Antonio Carlos. Helio Jaguaribe: a geração do nacional-desenvolvimentismo. In: PIMENTEL, José Vicente de Sá. Pensamento Diplomático Brasileiro. Formuladores e Agentes da Política Externa (1750-1964). Brasília: FUNAG, 2013.

MALLEA, Rodrigo. La cuestión nuclear en la relación argentino-brasileña (1968-1984). Dissertação (Mestrado em Ciência Política) - Universidade do Estado do Rio de Janeiro, Rio de Janeiro, 2012.

MALLEA, Rodrigo; SPEKTOR, Matias. Introdução. In: MALLEA, Rodrigo; SPEKTOR, Matias; WHEELER, Nicolas J. (edt.). Origens da cooperação nuclear: uma história oral crítica entre Brasil e Argentina. Woodrow Wilson Center for Scholars; FGV, 2015.

MARINHO, Jonas Teixeira. Da corrida atômica à cooperação: a questão nuclear nas relações Brasil-Argentina. Conjuntura Austral, v. 8, n. 41, abr./maio 2017. 
MATHIAS, Suzeley Kalil, GUZZI, André Cavaller e GIANNINI, Renata Avelar. Aspectos da integração regional em defesa no Cone Sul. Revista Brasileira de Política Internacional, v. 51, n. 1, p. 70-86, 2008.

MELLO, Leonel Itaussu Almeida. Argentina e Brasil: A balança de poder no Cone Sul. São Paulo: Annablume Editora, 1996.

MILANI, C. R. S.; PINHEIRO, L.; DE LIMA, M. R. S. Brazil's foreign policy and the 'graduation dilemma'. International Affairs, v. 93, n. 3, p. 585-605, 2017.

MOTTA, Marly. As peças do quebra-cabeças: Rex Nazaré e a política Nuclear Brasileira. História Oral, v. 13, n. 2, p. 115-35, 2010.

OELSNER, Andrea. International Relations in Latin America: Peace and Security in the Southern Cone. Nova York e Londres: Routledge, 2005.

OLIVEIRA, Antonio A.; CANTO, Odilon Marcuzzo do. ABACC, un ejemplo de integración y transparencia. IX Latin American IRPA Regional Congress on Radiation Protection and Safety, 2013.

OLIVEIRA, Odete Maria de. Integração nuclear Brasil-Argentina: uma estratégia compartilhada. Florianópolis: Ed. da UFSC, 1996.

ORSOLINI, Mario H. O plano nuclear argentino: um modelo de ação estratégica. Política e Estratégia, v. 2, n.4, p. 518-26, 1984.

PEREIRA, Leandro da Silva Batista. Vitória na derrota: Álvaro Alberto e as origens da política nuclear brasileira. Dissertação de mestrado, Fundação Getúlio Vargas - CPDOC, Rio de Janeiro, 2013.

PINGUELLI ROSA, L. A Batalha Atômica. Revista Nossa História, 2006. Disponível em: <http://www.coppe.ufrj.br/pt-br/a-batalha-atomica\#>. Acesso em 10 jun. 2018.

PINHEIRO, Letícia. Traídos pelo desejo: um ensaio sobre a teoría e a prática da política externa Brasileira contemporânea, Contexto Internacional, 22: 2, July-Dec. 2000, pp. 305-35.

PUIG, Juan Carlos. Integración y autonomía de América Latina en las postrimerías del siglo XX. Integración latinoamericana, enero-febrero 1986.

REDICK, John R. The Tlatelolco Regime and Nonproliferation in Latin America. International Organization, v. 35, n.1, p.103-34, 1981.

REDICK, John R. Nuclear Illusions: Argentina and Brazil. The Henry L. Stimson Center, 1995.

RONCONI, G. B.; ZUCATTO, G.; HACK, G.; SILVA, J. A. R. Militares, desenvolvimento e política externa: a questão nuclear como transferência de tecnologia. In: SILVA, A. L. R.; MARTINS, J. M. Q. (Orgs.) Estudos de Caso em Política Externa Brasileira 1930-1985. Porto Alegre: ISAPE, 2015.

RUIZ, José Briceño; SIMONOFF, Alejandro. La Escuela de la Autonomía, América Latina y la teoría de las relaciones internacionales. Estudios Internacionales, v. 185, 2016, p. 39-72.

PARADISO, José. Um lugar no mundo: A Argentina e a busca da identidade internacional. Rio de Janeiro: Civilização Brasileira, 2005.

SÁBATO, Jorge A. Energía atómica en Argentina. Estudios Internacionales, v.7, n.3, p.332-57, 1968.

SANTOS, Theotonio dos. A crise da teoria do desenvolvimento e as relações de dependência na América Latina. In: JAGUARIBE, Helio; FERRER, Aldo; WIONCZEK, Miguel S.; SANTOS, Theotonio dos. Dependência político-econômica da América Latina. São Paulo: Loyola, 1976. 
SOARES DE LIMA, Maria Regina. The Political Economy of Brazilian Foreign Policy: Nuclear Energy, Trade and Itaipu. Brasília: FUNAG, 2013.

SOARES, Samuel Alves; LIMA, Raphael Camargo. No limbo da dissonância: Argentina e Brasil no campo da Defesa. In: CARMO, C. A., WINAND, E. C. A.; BARNABÉ, I. R.; PINHEIRO, O. L. M. (Orgs.) Relações Internacionais: Olhares Cruzados. Brasília: Fundação Alexandre Gusmão. p. 315-350, 2013.

SOLINGEN, Etel. The Political Economy of Nuclear Restrain. International Security, v. 19, n. 2, 1994.

SOTOMAYOR, Arturo C. Civil-Military Affairs and Security Institutions in the Southern Cone: The Sources of Argentine-Brazilian Nuclear Cooperation. Latin American Politics and Society, v. 46, n. 4, 2006.

VARGAS, Everton Vieira. Átomos na integração: a aproximação Brasil-Argentina no campo nuclear e a construção do MERCOSUL. Revista Brasileira de Política Internacional, v. 40, n. 1, p. 41-74, 1997.

VIGEVANI, Tullo; CEPALUNI, Gabriel. A política externa de Lula da Silva: a estratégia da autonomia pela diversificação. Contexto internacional, v.29, n.2, 2007, pp.273-335.

VIGEVANI, Tullo; RAMANZINI JR, Haroldo. Autonomia e integração regional e Política Externa Brasileira: Mercosul e Unasul. Dados, v. 57, 2014.

WENDT, Alexander. Social Theory of International Politics. New York: Cambridge University Press, 2000.

WROBEL, Paulo S. Brazil, the non-proliferation treaty and Latin America as a nuclear weapon-free zone. Brasília: FUNAG, 2017. 


\title{
RESUMO
}

O objetivo no artigo é analisar o papel das ideias de autonomia e desenvolvimento nas atividades e nos posicionamentos de Argentina e Brasil em matéria nuclear, para compreender os impactos na promoção da cooperação bilateral. O relacionamento entre Argentina e Brasil é historicamente marcado por oscilações entre tônicas de rivalidade e cooperação. No campo nuclear não há diferenças substantivas e foi inicialmente caracterizado por competição e desconfianças, sendo progressivamente alterado para uma postura de aproximação e construção da confiança mútua. Autonomia e desenvolvimento podem ser entendidos como noções presentes nas deliberações realizadas pelos e nos países e que permitiram a identificação de valores e desafios comuns. Autonomia e desenvolvimento serviram como um primeiro eixo de contato para a cooperação em uma temática sensível e relevante na segunda metade do século XX, desde o início dos esforços em matéria de tecnologia nuclear nos anos 1950 até o estabelecimento de um novo patamar para as relações bilaterais no início dos anos 1990.

Palavras-chave: Argentina-Brasil; Cooperação Nuclear; Autonomia-Desenvolvimento.

\begin{abstract}
The aim of this paper is to analyze the role of the ideas of autonomy and development in the activities and positions of Argentina and Brazil in nuclear matters, to understand the impacts on the promotion of bilateral cooperation. The relationship between Argentina and Brazil has historically been marked by oscillations between rivalry and cooperation. In the nuclear field, there are no substantive differences and were initially characterized by competition and distrust, being progressively changed to a posture of approach and building mutual trust. Autonomy and development can be understood as notions present in the deliberations held by and in countries that allowed the identification of common values and challenges. Autonomy and development served as the first point of contact for cooperation on a sensitive and relevant issue in the second half of the twentieth century, from the beginning of nuclear technology efforts in the 1950s to the establishment of a new level for bilateral relations in the early 1990s from the 1990s.
\end{abstract}

Keywords: Argentina-Brazil; Nuclear cooperation; Autonomy-Development.

COPYRIGHT:

Este é um artigo publicado em acesso aberto e distribuição sob os termos da Licença Creative Commons de Atribuição Não-Comercial Compartilha-Igual 4.0 Internacional (CC BY-NC-SA 4.0), que permite seu uso, distribuição e reprodução em qualquer meio, bem como sua transformação e criações a partir dele, desde que o autor e a fonte originais sejam creditados. Ainda, o material não pode ser usado para fins comerciais, e no caso de ser transformado, ou servir de base para outras criações, estas devem ser distribuídas sob a mesma licença que o original.

This is an open-access article distributed under the terms of a Creative Commons Attribution-NonCommercial-ShareAlike 4.0 International License (CC BY-NC-SA 4.0), which permits its use, distribution and reproduction in any medium or format, as well as to transform and build upon the material, provided that the original author and source are credited. Furthermore, the material cannot be used for commercial purposes, and in case it is transformed, or used as bases for other creations, these must be distributed under the same license as the original. 